\title{
Desenvolvimento de um Ambiente Educacional Interativo Móvel como suporte para professores do ensino fundamental.
}

\author{
Sergio Ferreira do Amaral - Faculdade de Educação da UNICAMP \\ amaral@unicamp.br
}

\begin{abstract}
This article describes the construction of an educational interactive environment developed for use in the classroom. The environment favors the authorship and autonomy of teachers in the creation of activities, enabling them to be prepared in accordance with the need of the students, providing an effective learning.

Resumo.Este artigo descreve a construção de um ambiente educacional interativo móvel, desenvolvido para utilização em sala de aula. O ambiente favorece a autoria e a autonomia dos professores na criação das atividades, possibilitando que as mesmas sejam elaboradas de acordo com a necessidade dos alunos, proporcionando, dessa forma, uma aprendizagem efetiva.
\end{abstract}

\section{Introdução}

A entrada do tablet nas escolas, traz a necessidade de mudanças no cotidiano escolar, as quais podem ser traduzidas como quebra de paradigmas, constante formação dos professores, adaptação e reestruturação de espaços físicos objetivando alcançar a realização de atividades que, além de dinâmicas, façam parte do contexto social dos envolvidos.

O professor exerce papel primordial para que tais mudanças ocorram e, de acordo com DEMO (2007, p.85), "Cabe ao professor, em especial ao pedagogo, trabalhar a aprendizagem nos meios eletrônicos, diminuindo a distância hoje vigente entre a modernidade e o atraso didático”. O professor continua sendo uma figura importante no campo educacional, pois a relação direta com os alunos é mantida com o uso de recursos tecnológicos e, é a partir dessa relação que ocorre o processo de aprendizagem.

Partindo desse pressuposto, é descrito a seguir, a construção de um ambiente interativo mediatizado pela plataforma móvel, para utilização em sala de aula. O ambiente foi criado para favorecer a autoria e a autonomia dos professores na elaboração de atividades, de acordo com a necessidade dos alunos.

\section{O Ambiente Educacional}

O ambiente educacional deste trabalho objetiva dar suporte para a criação e utilização de conteúdos educacionais interativos. Trata-se de um ambiente eletrônico interativo de ensino em que professores criam atividades educacionais que serão executadas por seus alunos.

O ambiente possui dois módulos principais: o primeiro é composto por um ambiente de autoria onde professores criam as atividades. O segundo é voltado para os alunos e é composto por um ambiente que executa as atividades criadas. Este último é executado 
diretamente no tablet. Optou-se por hospedar o sistema na Web, pois permite que o sistema seja acessível por outros dispositivos como notebooks e PC.

O ambiente também possui outra característica: dar aos professores autonomia para construir suas atividades. O sistema não exige que o usuário possua conhecimentos técnicos de computação para conseguir gerar uma atividade.

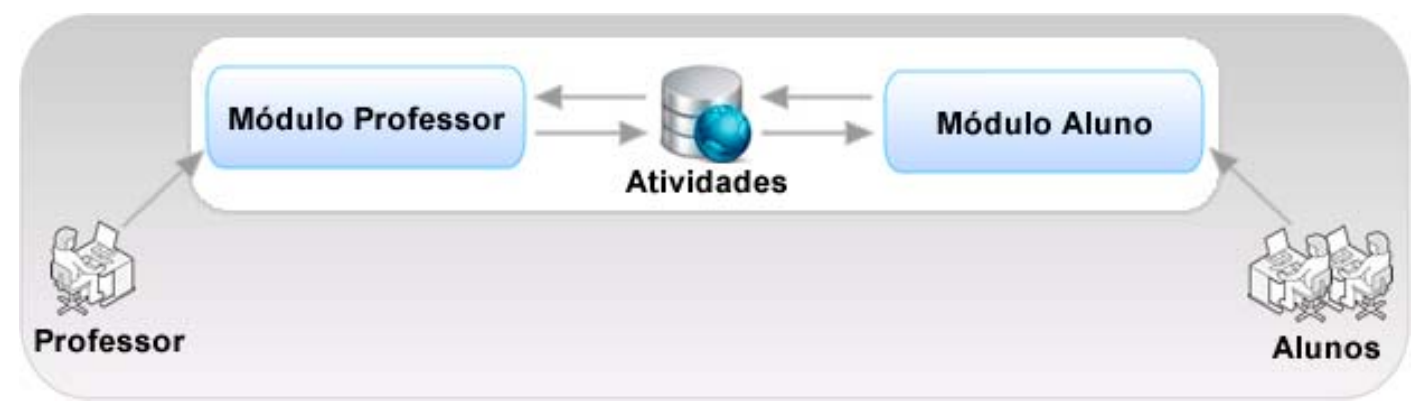

Figura 1. Esquema Geral da Arquitetura do Sistema

\section{Arquitetura do Sistema}

A arquitetura do sistema é organizada em dois módulos principais: o módulo professor e o módulo aluno. Os dois módulos acessam o mesmo banco de dados, realizando operações de leitura e escrita. A Figura 1, ilustra um esquema geral do sistema. Tanto os módulos do sistema como o banco de dados estão armazenados no mesmo servidor.

A Figura 2, apresenta os módulos do sistema de forma mais detalhada. Hospedados no servidor Web, os módulos professor e aluno interagem com uma área de atividades, cujos dados estão hospedado em um banco de dados no mesmo servidor. A interação acontece quando o professor cria atividades que serão posteriormente realizadas por alunos.

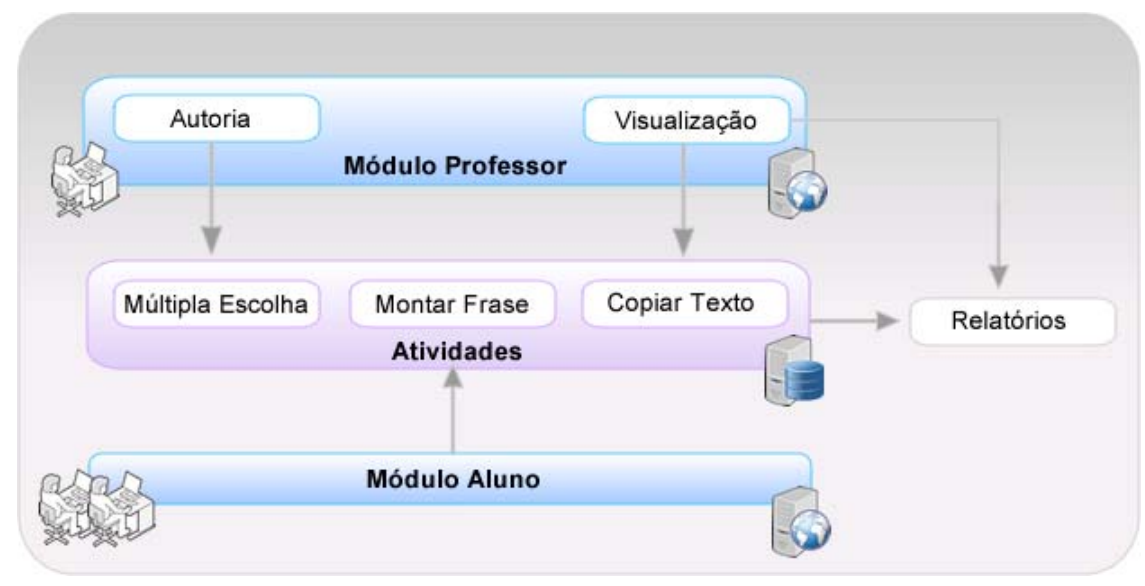

Figura 2. Diagrama dos Módulos 
As seções seguintes descrevem os módulos da Figura 2. Para melhor ilustrar as funcionalidades envolvidas, utilizou-se a técnica de Casos de Uso, pertencente à modelagem UML (UnifiedModelingLanguage), uma linguagem padrão para a especificação, visualização, construção e documentação dos artefatos do sistema desenvolvido (Object Management Group, 2012). Os casos de uso são utilizados para descrever as operações que o sistema deve cumprir para cada tipo de usuário.

\subsection{Módulo Professor}

Este módulo possui as ações que podem ser realizadas por um professor no sistema, como ilustra o Caso de Uso da Figura 3. Estas ações são a autoria e a visualização de relatórios. Em autoria, o professor irá construir as atividades que serão executadas por seus alunos: copiar texto, múltipla escolha e ordenar blocos. A construção destas atividades não exige que o professor possua conhecimentos técnicos de computação. $O$ sistema oferece recursos gráficos que permitem a construção dos artefatos através de funcionalidades simples como arrastar e soltar, selecionar e incluir texto, entre outros. A Figura 4 apresenta duas telas que ilustram as interfaces gráficas do módulo professor.

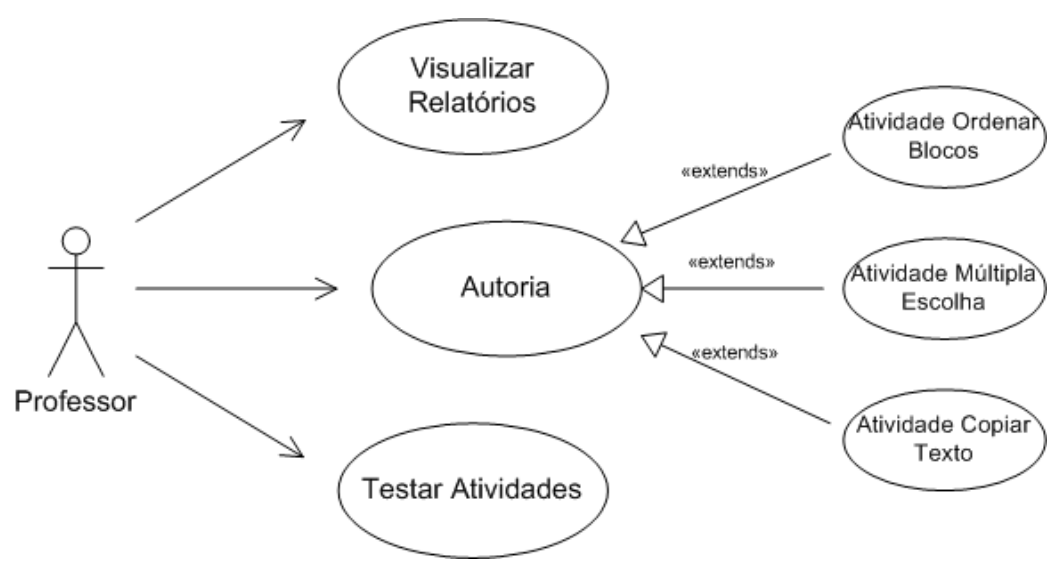

Figura 3. Caso de Uso - Professor

Plataforma de Autoria

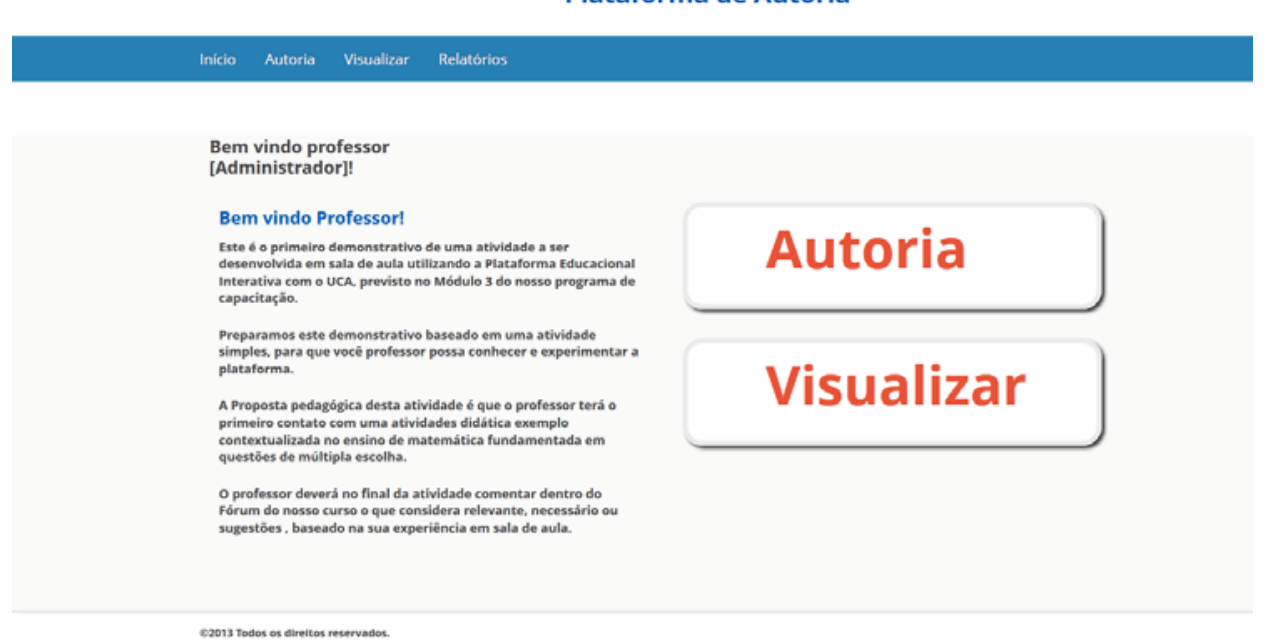

Figura 4. Módulo Professor 
Na área de visualização de relatórios é possível visualizar, de forma tabulada, os resultados das atividades que foram executadas por alunos. Desta forma, o professor poderá acompanhar o desempenho de seus alunos.

Além destas duas principais funcionalidades, o professor poderá também testar as atividades que construiu. Esta funcionalidade dá ao professor a possibilidade de verificar como resultado final da sua construção será visualizado e executado pelo aluno.

\subsection{Módulo Aluno}

Neste módulo o aluno irá executar as atividades construídas pelos professores (copiar texto, múltipla escolha e ordenar blocos), como ilustra o Caso de Uso da Figura 5. O aluno poderá ter uma ou várias atividades a executar. A Figura 6 ilustra a tela onde são disponibilizadas ao aluno as atividades que deverão ser executadas.

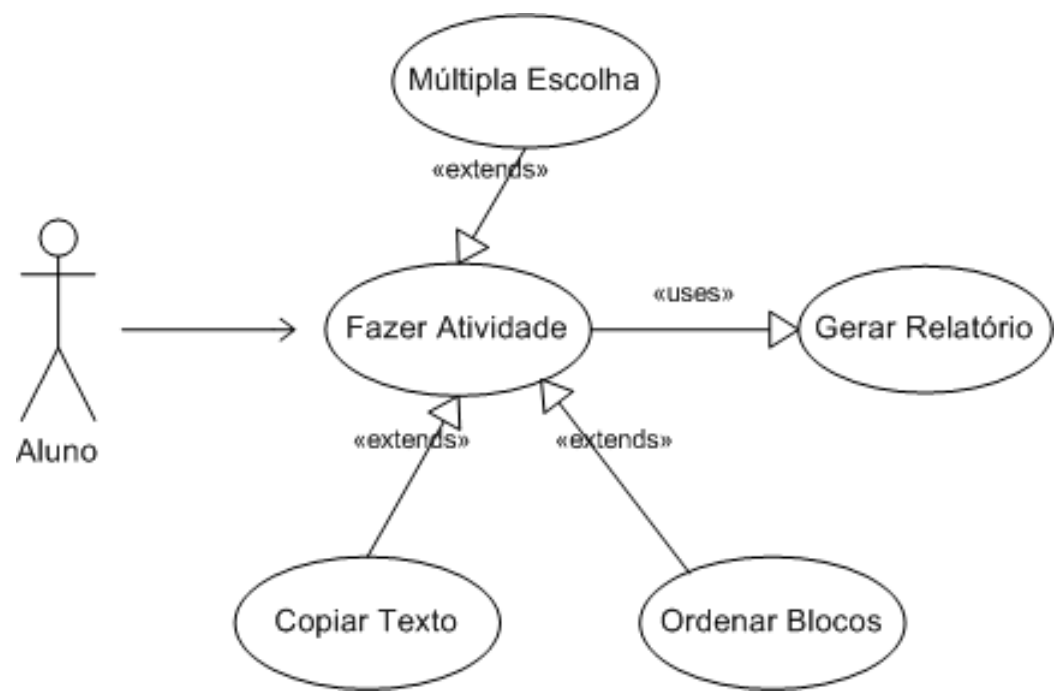

Figura 5. Caso de Uso - Aluno

\section{Bem-vindo:}

- Lista de Atividades •

Escrita de Palavras

Ordenar Frases

\section{Silabas}

Figura 6. Módulo Aluno 
Quando o aluno iniciar uma atividade, deverá executá-la até o final, sem interrupções. Somente será possível ir para uma próxima atividade quando encerrar a atividade corrente.

Enquanto o aluno executa uma atividade, as respostas, erros, acertos e o tempo utilizado para execução da tarefa serão armazenados. Estes valores serão utilizados para gerar relatórios a serem acessados pelos professores.

\subsection{Atividades}

As atividades não são um módulo do sistema, mas os artefatos criados pelos professores e executados pelos alunos. O sistema permite a criação de três tipos de atividades: copiar texto, múltipla escolha e ordenar blocos. Na atividade de copiar texto, ilustrada na Figura 7(c), o aluno irá ler uma frase e repeti-la digitando em uma caixa de texto. $\mathrm{O}$ objetivo é verificar se o aluno reproduziu corretamente o texto apresentado. Para esta atividade o atalho ctrl $+\mathrm{c} / \mathrm{ctrl}+\mathrm{v}$ (copiar/colar) foi desabilitado.

$\mathrm{Na}$ atividade múltipla escolha, Figura 7(b), é apresentada ao aluno uma pergunta sobre alguma disciplina - matemática, português,... - e um conjunto de respostas possíveis. $\mathrm{O}$ aluno deverá selecionar a resposta correta.

Na atividade ordenar bloco, Figura 7(a), é apresentado ao aluno uma frase e um conjunto de cinco blocos contendo cada trecho desta frase. Os blocos são apresentados desordenadamente e o objetivo é fazer o aluno ordenar os blocos para que fique de acordo com a frase apresentada.

A partir do momento em que o aluno inicia qualquer uma das três atividades, deverá executá-la até o final, não sendo possível o abandono da tarefa.

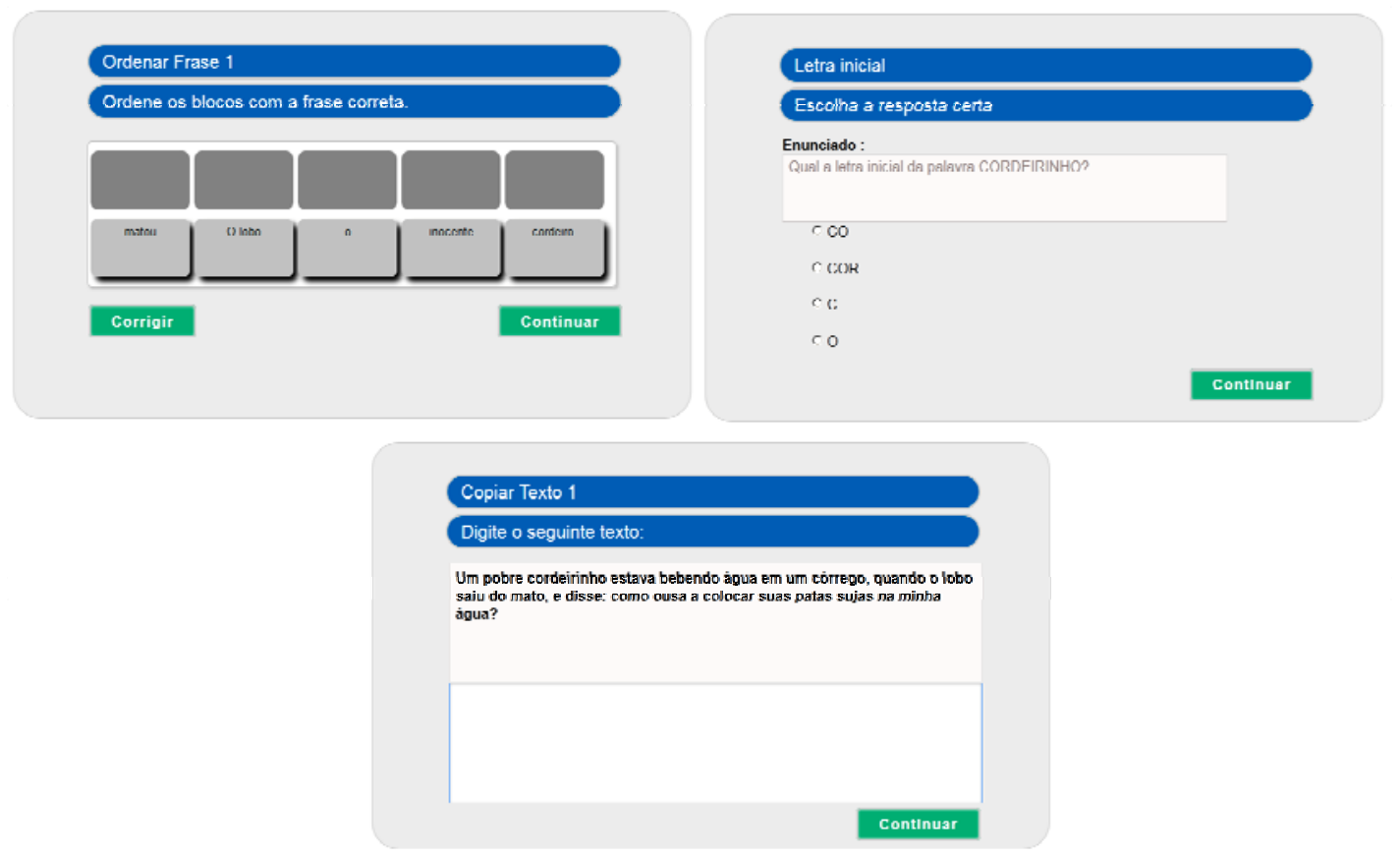

Figura 7. Tipos de Atividades 


\section{Implementação do Sistema}

A implementação da arquitetura do sistema foi realizada em camadas. Na produção de software, considera camada como uma referência a separação de responsabilidades. Esta organização é a chave para a independência entre os componentes para se alcançar eficiência, escalabilidade, reutilização e facilidade de manutenção. Para tanto, utilizouse a arquitetura MVC(Model - View - Controller), ilustrada na Figura 8.

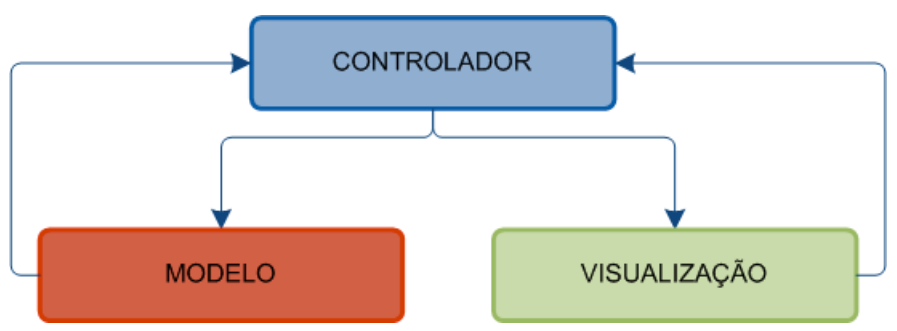

Figura 8. ModeloMVC

Esta arquitetura tem por objetivo separar o input do usuário do acesso aos dados e modelo de negócios por meio de três regras: modelo, controlador e visualização (BURBECK, 1992). O modelo representa a camada dos dados e permite a manipulação destes dados (criar, ler, atualizar e apagar). A visualização é responsável pela apresentação dos dados para o usuário. O controlador possui as regras de negócio que determinam como os dados do modelo serão manipulados e como serão apresentados de acordo com as solicitações do usuário.

A construção do sistema envolveu o uso de um conjunto de tecnologias Web, apresentadas na Figura 9. Para apresentação do sistema, foram utilizados XHTML e CSS (CascadingStyleSheets), que permite especificar a apresentação dos elementos em uma página web, tais como fontes, espaçamento, cores, entre outros, separadamente da estrutura do documento, simplificando a manutenção e modificação daspáginasWeb.

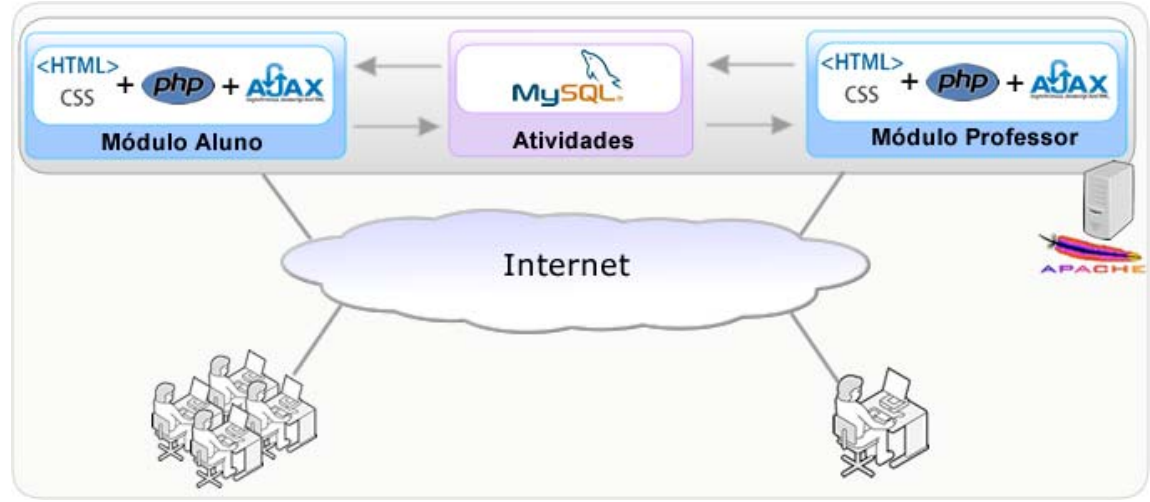

Figura 9. Diagrama Geral do Sistema

Para o processamento dos dados e acesso ao banco de dados foi utilizada a linguagem PHP (PHP Group, 2012). Em conjunto, foi utilizado o AJAX (AsynchronousJavascriptand $X M L$ ) para tornar o sistema mais interativo ao permitir solicitações assíncronas de informação. 
Todos os dados são armazenados em um banco de dados remoto. Para tanto, utilizou-se o MySQL (MySQL, 2012). Tanto os arquivos do sistema como o banco de dados foram hospedados em um mesmo servidor Apache (The Apache Software Foundation,2012).

A base de dados foi construída a partir das operações e funcionalidades requeridas, mostradas anteriormente nos casos de usos. A organização dos dados utilizados pelo sistema é descrito pelo diagrama E-R (Entidade Relacionamento) mostrada na figura 10.

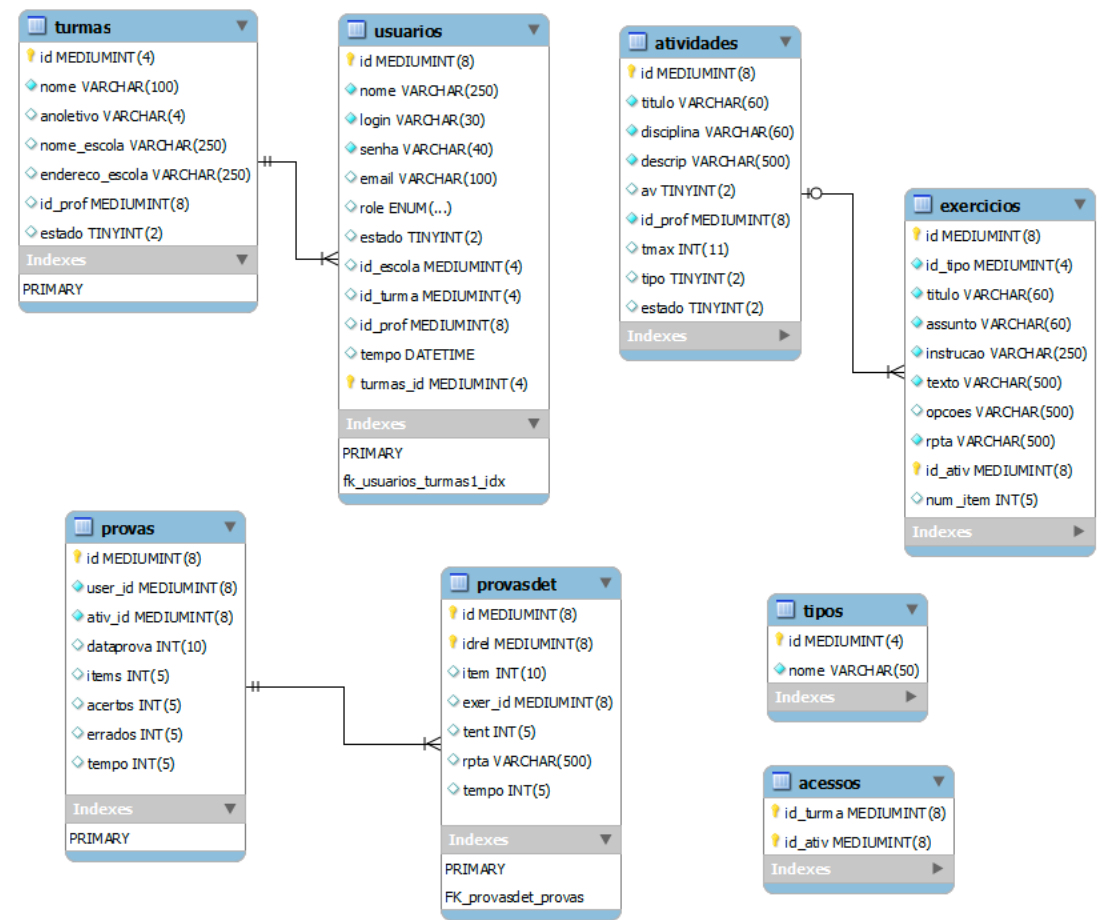

Figura 10. Diagrama ER

\section{Considerações Finais}

Neste trabalho apresentou-se o desenvolvimento de um ambiente de autoria e suporte educativo meditizado pela plataforma móvel. O ambiente envolve a participação do professor e do aluno em sua utilização, onde o professor constrói atividades que serão ministradas em sala de aula com os alunos. Por não exigir conhecimentos especializados, o sistema oferece ao professor autonomia para a construção dos artefatos e a possibilidade de enriquecer o conteúdo de suas aulas.

O sistema não precisa de instalação. A distribuição e atualizações são realizadas no servidor. O sistema pode ser usado tanto numa rede local como na internet. Desta forma, torna-se fácil a utilização no tablet.

\section{Referências}

Burbeck, S. (1992) "How to use Model-View-Controller (MVC)". http://stww.cs.uiuc.edu/users/smarch/st-docs/mvc.html 
Demo, Pedro. (2007), Professor do futuro e reconstrução do conhecimento. $5^{\mathrm{a}}$ Ed. Petrópolis, RJ: Vozes.

MySQL, Data Base Management System, Sun Microsystems, http://www.mysql.com, acessado em 2012.

Object Management Group, Inc, UML Resource Page, http://www.uml.org, acessado em 2012.

PHP Group, http://www.php.net/manual/pt_BR/language.oop5.basic.php, acessado em 2012.

The Apache Software Foundation, Apache HTTP Server Project, http://httpd.apache.org, acessado em 2012. 